\title{
Weight growth of triplet infants from birth to twelve years of age
}

\section{Yokoyama, Yoshie}

\section{2}

Yokoyama , Y , Pitkäniemi , J M , Kaprio , J \& Silventoinen, K 2012 , ' Weight growth of triplet infants from birth to twelve years of age ', Twin Research and Human Genetics, vol. 15 , no. 5 , pp. $672-679$. https://doi.org/10.1017/thg.2012.42

http://hdl.handle.net/10138/234281

https://doi.org/10.1017/thg.2012.42

publishedVersion

Downloaded from Helda, University of Helsinki institutional repository.

This is an electronic reprint of the original article.

This reprint may differ from the original in pagination and typographic detail.

Please cite the original version. 


\title{
Weight Growth of Triplet Infants From Birth to Twelve Years of Age
}

\author{
Yoshie Yokoyama, ${ }^{1}$ Janne Pitkäniemi, ${ }^{2}$ Jaakko Kaprio, ${ }^{2,3,5}$ and Karri Silventoinen ${ }^{4}$ \\ ${ }^{1}$ Department of Community Health Nursing, Osaka City University, Osaka, Japan \\ ${ }^{2}$ Hjelt Institute, Department of Public Health, University of Helsinki, Helsinki, Finland \\ ${ }^{3}$ Department of Mental Health and Substance Abuse Services, National Institute for Health and Welfare, Helsinki, Finland \\ ${ }^{4}$ Population Research Unit, Department of Social Research, University of Helsinki, Helsinki, Finland \\ 5 Institute for Molecular Medicine, University of Helsinki, Helsinki, Finland
}

\begin{abstract}
We analyzed the characteristics associated with the growth in weight of Japanese triplets from birth to 12 years of age. The study included 376 mothers and their 1,128 triplet children, who were born between 1978 and 2006. Data were collected through a mailed questionnaire sent to the mothers asking for information recorded in medical records. For these births, data on triplets' weight growth, gestational age, sex, parity, maternal age at delivery, maternal height, and maternal body mass index were obtained from records in the Maternal and Child Health Handbooks and records in the school where children receive health check-ups. The weight deficit of the triplets compared to the general population of Japan remained between $10 \%$ and $17 \%$ until 12 years of age. Moreover, at 12 years of age, the differences of weight between the general population and triplets were approximately $-4.75 \mathrm{~kg}$ for boys and $-6.00 \mathrm{~kg}$ for girls. Very low birth weight had the strongest contribution to body weight until 8 years of age. After 8 years of age, maternal body mass index was a significant factor affecting the weight of triplets until 12 years of age.
\end{abstract}

Keywords: triplet, body weight, very low birth weight, maternal body mass index

It is well known that the growth patterns of twins and triplets during pregnancy differ from those of singletons. Studies on the birth weight of twins or triplets have been conducted in many countries (Arbuckle et al., 1993; Buckler \& Green 1994; Glinianaia et al., 2000; Kato, 2004; Min et al., 2000; Min et al., 2004; Orlebeke et al., 1993). Triplets are typically born prematurely, and $40-50 \%$ of them weigh less than 1,500 g at birth (Kato, 2004; Ziadech, 2000). In the meanwhile, a number of studies on the postnatal growth of twins have been conducted (Akerman \& Fischbein, 1992; Alfieri et al., 1987; Luke et al., 1995; Buckler \& Green, 2004; Ooki \& Yokoyama, 2004; Silventoinen et al., 2007; Wilson, 1976; Wilson, 1979). The weight deficit of twins is greatest at birth but decreases dramatically during the first year of life because of rapid catch-up growth, reaching as little as approximately $2 \%$ for weight, by 4 years of age (Buckler \& Green, 1994; Ooki \& Yokoyama, 2004). However, there are few previous studies on the postnatal growth of triplets in the world.

The special features of multiple pregnancies have potential effects also on the further life of twins and tripletons since it is indicated that low birth weight is a risk factor for adverse health and neurodevelopmental outcomes (Arnoudse-Moens et al., 2009; Bhutta et al., 2002;
Wadhawan et al., 2011). In addition, children who demonstrate catch-up growth are found to be at greatest risk for alteration in metabolism, hormonal output, and distribution of cardiac output, which result in obesity, diabetes, and cardiovascular disease in middle age (Cianfrani et al., 1999; Fall, 1995; Forsen et al., 1999; Law, 2001). Studies of the long-term growth of low birth weight infants including triplets, the majority of whom experience intrauterine and/or neonatal growth failure, may yield important information in this regard (Bukowski et al., 2001; Ehrenkranz et al., 1999; Hack, 1982).

Physical growth of triplets was found to be behind singletons even in mid-childhood in spite of the rapid catchup growth during the first year of life (Luke et al., 2006; Yokoyama et al., 2008; Yokoyama et al., 2009). However,

RECEIVED 14 October 2011; ACCEPTED 22 May 2012. First published online 3 July 2012.

ADDRESS FOR CORRESPONDENCE: Yoshie Yokoyama, Department of Community Health Nursing, Osaka City University, 1-517 Asahi-machi, Abeno-ku, Osaka 545-0051, Japan. E-mail: yyokoyama@nurs.osaka-cu.ac.jp 
there have been no reports of weight growth of triplets after 6 years of age. The purpose of this study was to analyze the characteristics of weight growth in Japanese triplets until 12 years of age by extending the follow-up time of our prior study (Yokoyama et al., 2008).

\section{Participants and Methods}

The participants of this study were recruited from the Osaka City University Higher Order Multiple Births Registry (Yokoyama, 2002; Yokoyama et al., 1995; Yokoyama et al., 2005), which consisted of 578 mothers with triplets who were born between 1978 and 2006. Mothers and their triplet children were enrolled also from several other sources, such as various Japanese Mother's Organizations for Higher Order Multiple Births and referrals from public health nurses.

Data were collected through a mailed questionnaire sent to the mothers asking for information available in medical records. For these births, data on triplets' weight growth, gestational age, sex, parity, and maternal age at delivery were obtained from the records in the Maternal and Child Health Handbooks. This handbook was established by the Maternal and Child Health Law in Japan and is provided to the expecting mother by the authorities after the report of pregnancy. The purpose of this handbook is the maintenance of maternal and child health, and it includes information on health check-ups during pregnancy, the condition of the newborn, the progress of infant growth, and periodic medical check-ups for the infant and vaccinations recorded by obstetricians or pediatricians. In addition, information on maternal weight/height and infertility treatment was obtained. We used body mass index (BMI) categories according to Japan Society for the Study of Obesity based on the definitions given by WHO (World Health Organization) BMI of less than $18.5 \mathrm{~kg} / \mathrm{m}^{2}$ as underweight; BMI of $18.5-24.9 \mathrm{~kg} / \mathrm{m}^{2}$ as normal weight; and BMI of more than $25 \mathrm{~kg} / \mathrm{m}^{2}$ as overweight or obese.

In Japan, the health check-up system after birth differs according to life stage. Until 6 years of age, children participate in health check-ups administered by the Ministry of Health, Labor and Welfare based on age, which is counted as actual weeks, months, or years after birth. The weight data of children based on health check-ups are routinely recorded in the Handbook. After 6 years of age, Japanese children receive health check-ups administered by the Ministry of Education, Culture, Sports, Science and Technology under the School Health Law. The weight measures from these school-based health check-ups are routinely recorded in the school records and made available to each family. Mothers have access to the school records from every grade and can check them directly. Mothers participating in this study were advised to refer to these records when completing the questionnaire. The weight growth data were assigned to the appropriate age groups on the basis of time (in days) since birth, which was calculated as the date at the check-up minus the child's birthday.

The response rate was $67.0 \%$. We had 1,164 triplet children having information on growth, but 36 triplets with unknown sex were excluded from the analyses. Ultimately, the subjects of this study were 376 mothers and their 1,128 triplet children. The mothers gave written informed consent to participate in the present study.

The significance of differences between mean values of gestational age was tested using analysis of variance ANOVA and multiple comparison posttest (Tukey pairwise comparisons) where the comparison was between the three groups of maternal BMI. The means and standard deviations of weight from birth to 12 years of age for triplets were calculated according to gestational age, very low birth weight, sex, parity, birth order, maternal age at triplet delivery, maternal height, and maternal BMI. The significance of differences between mean values of weight was tested using mix-model ANOVA where the comparison was between two or more groups in order to adjust for familial clustering (i.e., sets of triplets) as a random effect factor.

The statistical significance of regression coefficients of the covariates (factors), where assessed from the fixed effects and these were adjusted for familial clustering (i.e., sets of triplets) by introducing random effect in the linear mixed model. The associations of the factors with weight at 6,8 , 10 , or 12 years of age were explored by the linear mixedeffects model. The factors associated with weight at 6,8 , 10 , or 12 years of age were explored by the linear mixedeffects multiple regression analysis. This was done in order to adjust for familial clustering as a random effect factor. We fitted separate models for body weight at $6,8,10$, and 12 years of age as dependent variables. The independent variables were very low birth weight, sex, birth order of triplets, gestational age, maternal BMI, or maternal height.

The selected percentiles (10th, 25th, 50th, 75th, and 90th) of weight were calculated according to age and sex. Smoothing of growth curves was performed by cubic polynomial functions. The weight deficit of the triplets was calculated as the percentage difference between the value of the general population and that of the triplets divided by the value of the general population. The weight deficits were calculated using mean values of the growth standards presented by the Ministry of Health, Labor and Welfare (Kato et al., 2001) and the Ministry of Education, Culture, Sports, Science and Technology (2009). The PASW statistical package, version 19.0 for Windows (2011) was used for the statistical analysis.

\section{Results}

Table 1 presents the number of participants according to sex and age at each age when weight data were available. Table 2 summarizes the characteristics of the participants. Gestational age at birth significantly differed by maternal 


\section{TABLE 1}

Number of Triplet Individuals With Weight Data at Different Ages by Sex

\begin{tabular}{lcc}
\hline Weight & Male & Female \\
\hline Birth & 567 & 548 \\
1 year 0-1 month & 186 & 172 \\
2 years 0-6 months & 248 & 243 \\
3 years 0-6 months & 273 & 269 \\
4 years 0-6 months & 194 & 185 \\
5 years 0-6 months & 185 & 192 \\
6-years 0-6 months & 199 & 186 \\
7-years 0-6 months & 135 & 126 \\
8-years 0-6 months & 121 & 108 \\
9-years 0-6 months & 107 & 112 \\
10-years 0-6 months & 93 & 91 \\
11-years 0-6 months & 66 & 63 \\
12-years 0-6 months & 46 & 43 \\
\hline
\end{tabular}

Note: Individuals had a varying number of weight measures.

\section{TABLE 2}

Major Characteristics of the Triplet Individuals

\begin{tabular}{|c|c|c|}
\hline \multirow[t]{7}{*}{ Gestational age (weeks) } & $\leq 28$ & 69 (6.1\%) \\
\hline & $29-32$ & 309 (27.4\%) \\
\hline & $33-36$ & 639 (56.6\%) \\
\hline & $37 \leq$ & $96(8.5 \%)$ \\
\hline & Unk̄nown & $15(1.3 \%)$ \\
\hline & $\begin{array}{l}\text { Mean } \pm \text { standard } \\
\text { deviation }\end{array}$ & $33.1 \pm 2.64$ \\
\hline & Range & $25-38$ \\
\hline \multirow[t]{8}{*}{ Birth weight (g) } & $<1,000$ & $76(6.7 \%)$ \\
\hline & $1,000 \leq a<1,500$ & $270(23.9 \%)$ \\
\hline & $1,500 \leq a<2,000$ & $510(45.2 \%)$ \\
\hline & $2,000 \leq a<2,500$ & $227(20.1 \%)$ \\
\hline & $2,500 \leq$ & $32(2.8 \%)$ \\
\hline & Unknown & $13(1.2 \%)$ \\
\hline & $\begin{array}{l}\text { Mean } \pm \text { standard } \\
\text { deviation }\end{array}$ & $1695.0 \pm 428.0$ \\
\hline & Range & $574-3078$ \\
\hline \multirow[t]{2}{*}{ Sex } & Male & $574(50.9 \%)$ \\
\hline & Female & $554(49.1 \%)$ \\
\hline \multirow{3}{*}{$\begin{array}{l}\text { Maternal parity at } \\
\text { triplet birth }\end{array}$} & Nullipara & $855(75.8 \%)$ \\
\hline & Multipara & $246(21.8 \%)$ \\
\hline & Unknown & 27 (2.4\%) \\
\hline \multirow{3}{*}{$\begin{array}{l}\text { Infertility treatment of } \\
\text { parents }\end{array}$} & Not used & $201(17.8 \%)$ \\
\hline & Used & $891(79.0 \%)$ \\
\hline & Unknown & $36(3.2 \%)$ \\
\hline \multirow[t]{7}{*}{ Maternal age of delivery } & $<25$ & $24(2.1 \%)$ \\
\hline & $25-29$ & $373(33.1 \%)$ \\
\hline & $30-34$ & $528(46.8 \%)$ \\
\hline & $35 \leq$ & $182(16.1 \%)$ \\
\hline & Unknown & $21(1.9 \%)$ \\
\hline & $\begin{array}{l}\text { Mean } \pm \text { standard } \\
\text { deviation }\end{array}$ & $31.0 \pm 3.58$ \\
\hline & Range & $20-42$ \\
\hline \multirow{4}{*}{ Maternal BMI } & $<18.5$ & $90(7.4 \%)$ \\
\hline & $18.5-24.9$ & $603(49.3 \%)$ \\
\hline & $25.0 \leq$ & $78(6.4 \%)$ \\
\hline & Unknown & $452(37.0 \%)$ \\
\hline
\end{tabular}

BMI and was $31.8 \pm 2.98$ weeks in women whose BMI is less than $18.5 \mathrm{~kg} / \mathrm{m}^{2}, 33.4 \pm 2.52$ weeks in women whose BMI is $18.5-24.9 \mathrm{~kg} / \mathrm{m}^{2}$, and $33.2 \pm 3.23$ weeks in women whose BMI is more than $25.0 \mathrm{~kg} / \mathrm{m}^{2}$. Gestational age of women whose BMI is less than $18.5 \mathrm{~kg} / \mathrm{m}^{2}$ was significantly shorter than that of women whose BMI is higher.

The 10th, 25th, 50th, 75th, and 90th percentiles of weight and the mean weight from birth to 12 years of age are presented in Figure 1. The range of 10th and 90th percentile weight at 12 years of age was from $30.4 \mathrm{~kg}$ to $52.8 \mathrm{~kg}$ in boys and $30.5 \mathrm{~kg}$ to $45.3 \mathrm{~kg}$ in girls.

Table 3 shows the mean weight at birth and at $6,8,10$, and 12 years of age analyzed according to gestational age, very low birth weight, sex, parity, birth order, maternal age at triplet delivery, maternal height, and maternal BMI. Females and triplets whose gestational age was earlier had a lower birth weight and lower weight at 6,8 , and 10 years of age; these differences were statistically significant, except for the sex difference for weight at 10 years of age. Very low birth weight infants had a lower birth weight and lower weight at 6,8 , and 10 years of age. Third-born neonates had a lower birth weight and lower weight at 6 years of age. Triplets born to shorter mothers had a lower weight at 6 years of age than triplet children born to taller mothers. Triplets born to women whose BMI is lower had a lower birth weight and lower weight at 12 years of age than triplet children born to women whose BMI is higher.

Table 4 shows the results of linear mixed effects multiple regression analysis of weight at $6,8,10$, or 12 years of age. We also present regression coefficients and $p$-values for each covariate. Very low birth weight has the strongest contribution on weight of triplets from 6 to 8 years of age, but also birth order affected weight at 6,8 , and 12 years of age. Sex affected weight at 8 years of age. Maternal height affected weight at 6 years of age, and maternal BMI affected weight at 8,10 , and 12 years of age.

The weight deficit of the triplets was more than $40 \%$ at birth relative to the growth standards of the general population (male, $-1.32 \mathrm{~kg}$; female, $-1.28 \mathrm{~kg}$ ). The deficit decreased rapidly within the first year of age, but fluctuated between $10 \%$ and $17 \%$ from 6 until 12 years of age (male, $-4.75 \mathrm{~kg}$; female, $-6.00 \mathrm{~kg}$ ) (Table 5).

\section{Discussion}

In the present study, the weight deficit of the triplets compared to the general population fluctuated between $10 \%$ and $17 \%$ for weight from 6 to 12 years of age. Moreover, at 12 years of age, the difference of weight between the general female population and female triplets was approximately $-6 \mathrm{~kg}$, whereas the difference of weight between the general male population and male triplets was approximately $-4 \mathrm{~kg}$. These results are similar to that reported by Powls et al. (1996) who found that very low birth weight children were significantly lighter than their normal birth weight peers at 12 years of age, with a mean deficit of $2.5 \mathrm{~kg}$. In addition, Hack et al. (2003) indicated that catch-up growth in weight occurred between 8 and 20 years among very low birth weight females but not among very low birth weight males who remained significantly smaller than their controls at 20 years of age. Further follow-up is needed to investigate whether triplets achieve normal weight later in life. 
(kg)

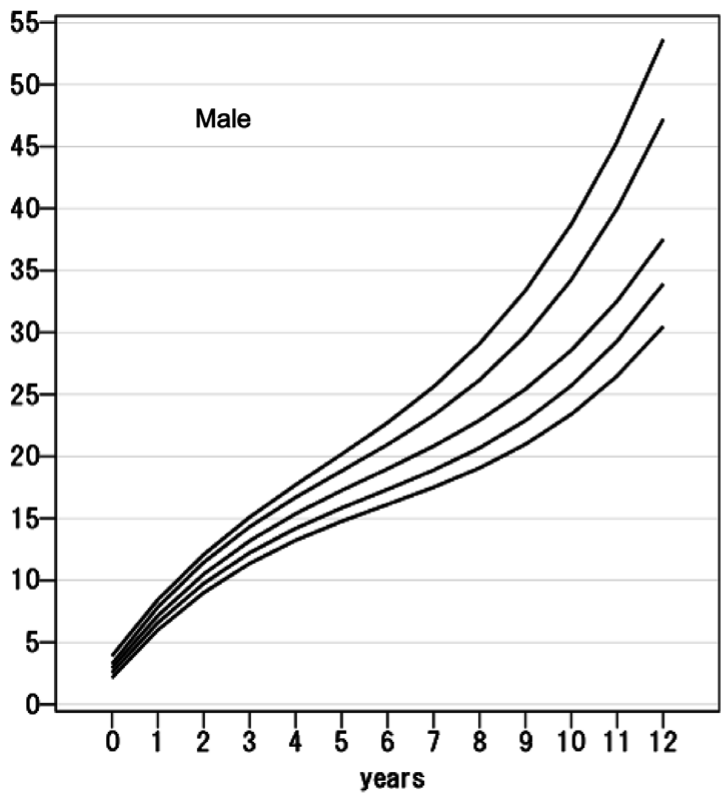

(kg)

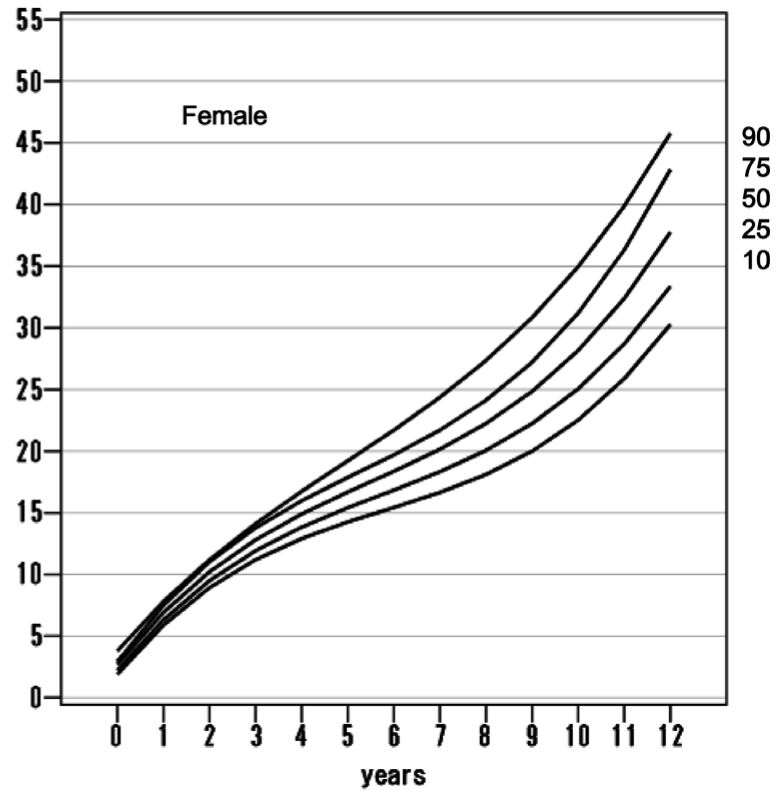

\section{FIGURE 1}

Body Weight of Triplets According to Age Percentiles From Birth to 12 Years of Age.

\section{TABLE 3}

Descriptive Statistics of Birth Weight and Weight at 6, 8, 10, and 12 Years of Age According Among Japanese Triplets and Comparisons Between Factors using ANOVA

\begin{tabular}{|c|c|c|c|c|c|c|c|c|c|c|c|c|c|c|c|c|}
\hline & & \multicolumn{3}{|c|}{ Birth weight (g) } & \multicolumn{3}{|c|}{6 years of age $(\mathrm{kg})$} & \multicolumn{3}{|c|}{8 years of age $(\mathrm{kg})$} & \multicolumn{3}{|c|}{10 years of age $(\mathrm{kg})$} & \multicolumn{3}{|c|}{$\begin{array}{c}12 \text { years of age } \\
(\mathrm{kg})\end{array}$} \\
\hline & & $N$ & Mean & $S D$ & $N$ & Mean & $S D$ & $N$ & Mean & $S D$ & $N$ & Mean & $S D$ & $N$ & Mean & $S D$ \\
\hline \multirow[t]{4}{*}{ Gestational age } & $\leq 28$ & 69 & 916.9 & $129.6^{* * *}$ & 19 & 16.69 & $1.88^{* *}$ & 6 & 20.58 & $2.52^{*}$ & 12 & 23.71 & $3.81^{* *}$ & 3 & 31.93 & 0.64 \\
\hline & 29-32 & 306 & $1,393.0$ & 263.1 & 111 & 17.84 & 2.19 & 57 & 21.95 & 3.80 & 44 & 26.84 & 4.65 & 18 & 34.08 & 7.96 \\
\hline & $33-36$ & 632 & $1,849.3$ & 301.8 & 213 & 18.76 & 2.65 & 141 & 24.66 & 4.54 & 115 & 30.99 & 6.25 & 53 & 40.42 & 6.27 \\
\hline & $37 \leq$ & 93 & $2,201.6$ & 361.9 & 42 & 18.53 & 2.15 & 25 & 23.21 & 2.82 & 13 & 31.18 & 4.91 & 15 & 41.02 & 8.78 \\
\hline \multirow{2}{*}{$\begin{array}{l}\text { Very low birth } \\
\text { weight infant }\end{array}$} & Yes & 346 & $1,205.4$ & $237.5^{* * * *}$ & 130 & 17.41 & $2.14^{* * *}$ & 60 & 21.13 & $3.03^{* * *}$ & 51 & 25.86 & $4.67^{* * *}$ & 22 & 33.66 & 7.24 \\
\hline & No & 769 & $1,915.3$ & 289.4 & 255 & 18.85 & 2.52 & 166 & 24.55 & 4.35 & 130 & 30.78 & 5.99 & 64 & 40.36 & 6.70 \\
\hline \multirow[t]{2}{*}{ Sex } & Male & 567 & $1,715.2$ & $439.2^{* * *}$ & 199 & 18.65 & $2.72^{*}$ & 121 & 24.53 & $4.82^{* * *}$ & 93 & 30.51 & 7.05 & 46 & 39.75 & 8.51 \\
\hline & Female & 548 & $1,674.1$ & 415.4 & 186 & 18.06 & 2.19 & 108 & 22.81 & 3.52 & 91 & 28.54 & 4.82 & 43 & 38.10 & 6.25 \\
\hline \multirow[t]{2}{*}{ Maternal parity } & Primipara & 849 & $1,665.3$ & 421.4 & 295 & 18.28 & 2.32 & 180 & 23.39 & 4.03 & 138 & 29.01 & 5.92 & 68 & 38.46 & 7.19 \\
\hline & Multipara & 243 & $1,801.5$ & $447.3^{* *}$ & 76 & 18.53 & 2.67 & 40 & 23.91 & 3.71 & 34 & 30.01 & 4.41 & 15 & 40.37 & 8.80 \\
\hline \multirow{3}{*}{ Triplet birth order } & Firstborn & 372 & $1,759.6$ & $420.4^{* * *}$ & 128 & 18.49 & $2.73^{*}$ & 79 & 23.96 & 5.21 & 62 & 29.69 & 7.12 & 30 & 39.69 & $7.28^{*}$ \\
\hline & Second-born & 372 & $1,694.4$ & 433.8 & 128 & 18.62 & 2.39 & 75 & 24.07 & 3.68 & 61 & 29.92 & 5.51 & 30 & 40.14 & 8.32 \\
\hline & Third-born & 371 & $1,630.9$ & 421.0 & 129 & 17.99 & 2.31 & 75 & 23.11 & 3.89 & 61 & 28.99 & 5.62 & 29 & 36.97 & 6.66 \\
\hline \multirow{4}{*}{$\begin{array}{l}\text { Maternal age at } \\
\text { triplet delivery }\end{array}$} & $<25$ & 24 & $1,418.9$ & 373.0 & 9 & 16.63 & 1.51 & 3 & 22.90 & 2.82 & 6 & 26.20 & 0.81 & 3 & 34.67 & 1.21 \\
\hline & $25-29$ & 370 & $1,725.9$ & 431.0 & 93 & 18.54 & 2.36 & 63 & 23.30 & 4.18 & 65 & 28.80 & 5.17 & 25 & 37.68 & 8.05 \\
\hline & $30-34$ & 525 & $1,695.0$ & 431.4 & 208 & 18.39 & 2.44 & 117 & 23.64 & 4.00 & 88 & 29.46 & 6.14 & 42 & 39.15 & 7.85 \\
\hline & $35 \leq$ & 179 & $1,667.3$ & 418.0 & 64 & 17.98 & 2.25 & 37 & 23.36 & 3.70 & 16 & 30.07 & 5.23 & 13 & 40.80 & 5.49 \\
\hline \multirow{4}{*}{ Maternal height } & $<\overline{15} 5$ & 174 & $1,648.2$ & 370.1 & 77 & 17.38 & $1.84^{* *}$ & 47 & 23.22 & 3.26 & 41 & 28.65 & 5.47 & 24 & 37.70 & 7.95 \\
\hline & $155-159$ & 286 & $1,683.9$ & 457.5 & 121 & 18.15 & 2.70 & 74 & 22.76 & 3.76 & 69 & 28.20 & 4.97 & 26 & 37.98 & 7.71 \\
\hline & $160-164$ & 218 & $1,717.1$ & 462.8 & 89 & 18.78 & 2.14 & 59 & 24.17 & 3.65 & 38 & 30.04 & 4.64 & 24 & 40.25 & 8.01 \\
\hline & $165 \leq$ & 87 & $1,785.9$ & 426.6 & 37 & 19.26 & 2.52 & 17 & 25.27 & 6.65 & 12 & 34.13 & 9.66 & 6 & 40.90 & 4.72 \\
\hline \multirow[t]{3}{*}{ Maternal BMI } & $<18.5$ & 90 & $1,443.7$ & $415.5^{* * *}$ & 51 & 17.28 & 1.88 & 22 & 20.63 & 2.55 & 24 & 26.47 & 3.93 & 9 & 34.24 & $6.89^{*}$ \\
\hline & $18.5-24.9$ & 600 & $1,742.8$ & 423.0 & 243 & 18.41 & 2.38 & 155 & 23.67 & 3.95 & 127 & 29.48 & 5.40 & 66 & 38.08 & 6.83 \\
\hline & $25.0 \leq$ & 78 & $1,691.2$ & 470.9 & 37 & 18.03 & 2.46 & 30 & 23.83 & 3.86 & 12 & 29.46 & 7.87 & 6 & 48.58 & 7.55 \\
\hline
\end{tabular}

Note: $S D=$ standard deviation. All variables included in the model, ${ }^{*} p<.05,{ }^{* *} p<.01,{ }^{* * * *} p<.001$.

Compared with the general population of Japan, the weight deficit of Japanese twins is greatest at birth but decreased dramatically in the first $6-12$ months, reaching as little as approximately $2 \%$, around $1 \mathrm{~kg}$ for weight, by 6 years of age (Ooki \& Yokoyama, 2004). These trends were con- sistent with those reported by Buckler and Green (1994). Meanwhile, the weight deficit of the triplets compared to the general population was greatest at birth: more than $40 \%$. These deficits decreased within the first year of life, but were found to fluctuate between $4 \%$ and $9 \%$ for weight until 6 
TABLE 4

Result of Linear Mixed Effects Multiple Regression Analysis of Factors Associated With Body Weight at Ages 6, 8, 10, and 12 Years

\begin{tabular}{|c|c|c|c|c|c|}
\hline Dependent variable & Independent variable & & Beta & $95 \% \mathrm{Cl}$ & $p$ \\
\hline \multirow[t]{10}{*}{ Weight at 6 years } & \multirow[t]{2}{*}{ Very low birth weight } & No & 1.014 & \multirow[t]{2}{*}{$0.426,1.601$} & \multirow[t]{2}{*}{$p=.001$} \\
\hline & & Yes & 0 & & \\
\hline & \multirow[t]{2}{*}{ Sex } & Male & 0.405 & \multirow[t]{2}{*}{$-0.017,0.828$} & \multirow{2}{*}{$p=.060$} \\
\hline & & Female & 0 & & \\
\hline & \multirow[t]{3}{*}{ Birth order in triplets } & Firstborn & 0.387 & $-0.056,0.830$ & \multirow{3}{*}{$\begin{array}{l}p=.087 \\
p=.004\end{array}$} \\
\hline & & Second-born & 0.657 & $0.213,1.101$ & \\
\hline & & Third-born & 0 & & \\
\hline & \multicolumn{2}{|l|}{ Gestational age } & 0.100 & $-0.034,0.235$ & \multirow{3}{*}{$\begin{array}{l}p=.143 \\
p=.227 \\
p=.002\end{array}$} \\
\hline & \multicolumn{2}{|l|}{ Maternal BMI } & 0.071 & $-0.045,0.188$ & \\
\hline & Maternal height & & 0.102 & $0.040,0.165$ & \\
\hline \multirow[t]{10}{*}{ Weight at 8 year } & \multirow[t]{2}{*}{ Very low birth weight } & No & 2.871 & $1.529,4.213$ & \multirow{2}{*}{$p<.001$} \\
\hline & & Yes & 0 & & \\
\hline & \multirow[t]{2}{*}{ Sex } & Male & 1.462 & $0.628,2.296$ & \multirow[t]{2}{*}{$p=.001$} \\
\hline & & Female & 0 & & \\
\hline & \multirow[t]{3}{*}{ Birth order in triplets } & Firstborn & 0.332 & $-0.531,1.195$ & \multirow{3}{*}{$\begin{array}{l}p=.447 \\
p=.026\end{array}$} \\
\hline & & Second-born & 0.995 & $0.120,1.871$ & \\
\hline & & Third-born & 0 & & \\
\hline & \multirow{2}{*}{\multicolumn{2}{|c|}{$\begin{array}{l}\text { Gestational age } \\
\text { Maternal BMI }\end{array}$}} & -0.108 & $-0.429,0.213$ & \multirow{3}{*}{$\begin{array}{l}p=.517 \\
p=.017 \\
p=.135\end{array}$} \\
\hline & & & 0.347 & $0.063,0.630$ & \\
\hline & Maternal height & & 0.105 & $-0.034,0.244$ & \\
\hline \multirow{10}{*}{ Weight at 10 years } & \multirow{2}{*}{ Very low birth weight } & No & 1.647 & $-0.541,3.835$ & \multirow[t]{2}{*}{$p=.139$} \\
\hline & & Yes & 0 & & \\
\hline & \multirow[t]{2}{*}{ Sex } & Male & 0.884 & $-0.599,2.368$ & \multirow[t]{2}{*}{$p=.241$} \\
\hline & & Female & 0 & & \\
\hline & Birth order in triplets & Firstborn & 0.468 & $-1.019,1.955$ & $p=.534$ \\
\hline & & Second-born & 1.087 & $-0.423,2.597$ & $p=.157$ \\
\hline & & Third-born & 0 & & \\
\hline & Gestational age & & 0.536 & $0.072,1.001$ & $p=.024$ \\
\hline & Maternal BMI & & 0.557 & $0.140,0.974$ & $p=.010$ \\
\hline & Maternal height & & 0.132 & $-0.074,0.338$ & $p=.203$ \\
\hline Weight at 12 years & Very low birth weight & No & 0.439 & $-3.887,4.764$ & $p=.840$ \\
\hline & & Yes & 0 & & \\
\hline & Sex & Male & 0.135 & $-2.663,2.933$ & $p=.924$ \\
\hline & & Female & 0 & & \\
\hline & Birth order in triplets & Firstborn & 2.608 & $-0.118,5.333$ & $p=.060$ \\
\hline & & Second-born & 3.117 & $0.299,5.935$ & $p=.031$ \\
\hline & & Third-born & 0 & & \\
\hline & Gestational age & & 0.741 & $-0.202,1.685$ & $p=.119$ \\
\hline & Maternal BMI & & 1.218 & $0.228,2.209$ & $p=.018$ \\
\hline & Maternal height & & 0.298 & $-0.126,0.722$ & $p=.159$ \\
\hline
\end{tabular}

TABLE 5

Size Deficit of Triplets for Mean Weight Compared With the General Population From Birth to 12 Years of Age

\begin{tabular}{lcc}
\hline & \multicolumn{2}{c}{ Body weight } \\
\cline { 2 - 3 } & Male (\%) & Female (\%) \\
\hline Birth & 43.59 & 43.45 \\
1 year 0-1 month & 9.17 & 7.30 \\
2 years 0-6 months & 5.69 & 6.59 \\
3 years 0-6 months & 5.83 & 6.39 \\
4 years 0-6 months & 7.99 & 8.62 \\
5 years 0-6 months & 10.08 & 10.23 \\
6 years 0-6 months & 13.24 & 14.01 \\
7 years 0-6 months & 10.35 & 13.06 \\
8 years 0-6 months & 10.47 & 14.24 \\
9 years 0-6 months & 11.74 & 14.90 \\
10 years 0-6 months & 11.32 & 16.79 \\
11 years 0-6 months & 11.58 & 16.88 \\
12 years 0-6 months & 10.67 & 13.61 \\
\hline Note: The weight deficit of the triplets was calculated as the percentage \\
difference between the mean value of the general population and \\
the mean of the triplets.
\end{tabular}

years of age (Yokoyama et al., 2008; Yokoyama et al., 2009). The difference of weight between the general population and triplets was approximately $1.8 \mathrm{~kg}$ at 6 years of age.
Meanwhile, when adjusting for gestational age and other confounding factors, very low birth weight had the strongest contribution to body weight at 6 and 8 years of age. It is indicated that deficient growth in twins between the age of 2 and 9 years was most evident in those light at birth (Buckler \& Green, 2008). Moreover, Powls et al. (1996) indicated that very low birth weight children had a higher risk of lower weight later in life and this difference was more pronounced in girls. It is probable that very low birth weight affects growth of weight in triplets. Infants with very low birth weight may need careful and extensive longitudinal followup.

Sex was a significant factor affecting weight at 8 years of age. Male triplets were heavier than females. This result is in accordance with previous reports on twins at birth (Kato, 2004; Ooki \& Yokoyama, 2004) and singletons (Britton et al, 1993). The effects of parity and maternal age at triplet delivery were very small and mostly disappeared at early age. In the present study, lasting effects of gestational periods and birth weight on body weight until 10 years of age were observed. However, the growth standards of the 
general population did not correct the effects of gestational age and birth weight to reflect the actual condition of physical growth. The present data should be treated in the same way in order to estimate the difference between the general population and triplets. Therefore in the present study, the growth charts for the triplets were differentiated only according to sex.

In height growth of triplets, maternal height was found to have significant effect not only on birth length but also on height during childhood (Yokoyama et al., 2011). However, our results showed that maternal height affected weight only at 6 years of age and after that the influence disappeared. On the other hand, maternal BMI was found to be a significant factor affecting the weight of triplets from 8 to 12 years of age. Parental obesity has been identified as one of the strongest risk factors for childhood obesity in singletons (Bundered et al., 2001; Burke et al., 2001; James et al., 2001; Reilly \& Dorosty, 1999), and childhood obesity and longitudinal changes in childhood weight have a major heritable component (Silventoinen et al., 2009; Silventoinen et al., 2010). In addition, it is indicated that parental leanness confers significant protection against the development of overweight in children (Semmler et al., 2009). These results suggest that maternal physique has a significant effect not only on weight in singletons during childhood but also on weight of triplets, probably reflecting the role of genetic factors masked at the early life by the special features of tripleton pregnancies but becoming visible at the later life.

Regarding other factors associated with weight of triplets, we found a small but persistent birth order effect: the thirdborn triplet was lighter than the second-born or the firstborn triplet. Previous studies in twins have reported similar results at birth (Buckler \& Green, 1994; Glinianaia et al., 2000) and from 3 to 12 years of age (Silventoinen et al., 2007). Moreover, Lamb et al. (2011) reported that the thirdborn trizygotic triplets were lighter than the second-born or the firstborn trizygotic children. The background of this effect needs more detailed research, but in twins, the firstborn (and heavier) twin was found to have a heavier placenta and a more optimal cord insertion (Gielen et al., 2007). Possibly triplets higher in birth order are more optimally positioned with respect to nutrients intake. The persistence of this birth order effect suggests that prenatal factors can have long-lasting effects on body weight.

A limitation of the present study was that these data were semilongitudinal. Specifically, data on the same individual were used according to the recorded times. Some of our participants provided most of longitudinal data. On the other hand, others provided data from birth to 6 years of age. Additionally, the number of participants in each age group varied considerably as some children were younger than 12 years at the time of the survey. Consequently, the range of measurements in each group becomes small, especially at 12 years of age. However, since the mothers re- ported the growth of their children retrospectively based on records, there is no age-related dropout in our data. Data on zygosity, maternal smoking, previous obstetric outcome, and maternal weight gain during pregnancy are also lacking in this study, and it has been suggested that these factors are associated with weight growth (Lamb et al., 2011; Luke et al., 2002; Ooki \& Yokoyama, 2003; Vogazianos et al., 2005).

In conclusion, triplets are lighter than singletons and the weight deficit of the triplets compared to the general population of Japan remained between $10 \%$ and $17 \%$ from 6 to 12 years of age. Very low birth weight had the strongest contribution to body weight until 8 years of age. After 8 years of age, maternal BMI was found to be a significant factor affecting the weight of triplets until 12 years of age. Further follow-up of the triplets should reveal whether their growth catches up with singletons before adulthood.

\section{Acknowledgments}

The authors would like to gratefully acknowledge the help of Kenka Lee in the data analysis. This research was supported by Ministry of Education, Science, Sports and Culture, Grant-in-Aid for Scientific Research (B), 2008-2012. The Academy of Finland Centre of Excellence in Complex Disease Genetics supported the participation of JK, KS, and JP.

\section{References}

Akerman, B. A., \& Fischbein, S. (1992). Within-pair similarity in $\mathrm{MZ}$ and $\mathrm{DZ}$ twins from birth to eighteen years of age. Acta Geneticae Medicae et Gemellologiae, 41, 155164.

Alfieri, A., Gatti, I., \& Alfieri, A. C. (1987). Weight and height growth in twins and children born in the last decade. Acta Geneticae Medicae et Gemellologiae, 36, 209-211.

Arbuckle, T. E., Wilkins, R., \& Sherman, G. J. (1993). Birth weight percentiles by gestational age in Canada. Obstetrics and Gynecology, 81, 39-48.

Arnoudse-Moens, C. S. H., Weisglas-Kuperus, N., van Goudoever, J. B., \& Oosterlaan, J. (2009). Meta-analysis of neurobehavioral outcomes in very preterm and/or very low birth weight children. Pediatrics, 124, 717728.

Bhutta, A. T., Clevels, M. A., Casey, P. H., Cradok, M. M., \& Anand, K. J. S. (2002). Cognitive and behavioral outcomes of school-aged children who were born preterm - A metaanalysis. Journal of the American Medical Association, 288, 728-737.

Britton, J. R., Britton, H. L., Jennett, R., Gaines, J., \& Daily, W. J. (1993). Weight, length, head and chest circumference at birth in Phoenix, Arizona. Journal of Reproductive Medicine, 38, 215-222.

Buckler, J. M. H., \& Green, M. (1994). Birth weight and head circumference standards for English twins. Archives of Diseases in Childhood, 71, 516-521. 
Buckler, J. M., \& Green, M. (2004). A comparison of the early growth of twins and singletons. Annals of Human Biology, 31, 311-332.

Buckler, J. M., \& Green, M. (2008). The growth of twins between the ages of 2 and 9 years. Annals of Human Biology, 35, 75-92.

Bukowski, R., Gahn, D., Denning, J., \& Saade, G. (2001). Impairment of growth in fetuses destined to deliver preterm. American Journal of Obstetrics and Gynecology, 185, 463467.

Bundered, P., Kitchner, D., \& Buchan, I. (2001). Prevalence of overweight and obese children between 1989 and 1998: Population based series of cross sectional studies. BMJ, 322, 326-328.

Burke, V., Bellin, L. J., \& Dunbar, D. (2001). Family lifestyle and parental body mass index as predictors of body mass index in Australian children: A longitudinal study. International Journal of Obesity and Related Metabolic Disorders, 25, 147-157.

Cianfrani, S., Germani, D., \& Branca, F. (1999). Low birthweight and adult insulin resistance: The 'catch-up growth' hypothesis. Archives of Diseases in Childhood: Fetal and Neonatal Edition, 81, F71-F73.

Ehrenkranz, R. A., Younes, N., Lemons, J. A., Fanaroff, A. A., Donovan, E. F., Wright, L. L., Katsikiotis, V., Tyson, J. E., Oh, W., Shankaran, S., Bauer, C. R., Korones, S. B., Stoll, B. J., Stevenson, D. K., \& Papile, L. A. (1999). Longitudinal growth of hospitalized very low-birth-weight infants. Pediatrics, 104, 280-289.

Fall, C. H. D., Osmond, C., Barker, D. J. P., Clark, P. M. S., Hales, C. N., Stirling, Y., \& Meade, T. W. (1995). Fetal and infant growth and cardiovascular risk factors in women. BMJ, 310, 428-432.

Forsen, T., Eriksson, J. G., Tomilehto, J., Osmond, C., \& Barker, D. J. P. (1999). Growth in utero and during childhood among women who develop coronary heart disease: Longitudinal study. BMJ, 319, 1403-1407.

Gielen, M., Lindsey, P. J., Derom, C., Loos, R. J. F., Derom, R., Nijhuis, J. G., \& Vlietinck, R. (2007). Twin birth weight standards. Neonatology, 92, 164-173.

Glinianaia, S. V., Skjaerven, R., \& Magnus, P. (2000). Birth weight percentiles by gestational age in multiple births. A population-based study of Norwegian twins and triplets. Acta Obstetrica Gynecologica Scandinavica, 79, 450-458.

Hack, M., Merkatz, J. R., Gordon, D., Jones, P. K., \& Fanaroff, A. A. (1982). The prognostic significance of postnatal growth in low-birth-weight infants. American Journal of Obstetrics and Gynecology, 143, 693-699.

Hack, M., Schluchter, M., Catar, L., Rahman, M., Cuttler, L., \& Borawski, E. (2003). Growth of very low birth weight infants to age 20 years. Pediatrics, 112, e30-e38.

James, P. T., Leach, R., Kalamara, E., \& Shayeghi, M. (2001). The worldwide obesity epidemic. Obesity Research, 9, 228s233s.

Kato, N. (2004). Reference birthweight range for multiple birth neonates in Japan. BMC Pregnancy and Childbirth, 4, $1-9$.
Kato, N., Okuno, T., \& Takaishi, M. (2001). Comments on the results of growth standards of Japanese children in 2000. Shoni Hoken Kenkyu (Journal of Child Health), 60, 707-720.

Lamb, D. J., Middeldorp, C. M., van Beijsterveldt, C. E. M., Vink, J. M., Haak, M. C., \& Boomsma, D. (2011). Birth weight in large series of triplets. BMC Pediatrics, 52, 11-24.

Law, C. (2001). Adult obesity and growth in childhood. BMJ, 323, 1320-1321.

Luke, B., Brown, M. B., Hediger, M. L., Misiunas, R. B., \& Anderson, E. (2006). Perinatal and early childhood outcomes of twins versus triplets. Twin Research and Human Genetics, 9, 81-88.

Luke, B., Leurgans, S., Keith, L., \& Keith, D. (1995). The childhood growth of twin children. Acta Geneticae Medicae et Gemellologiae, 44, 169-178.

Luke, B., Nugent, C., van de Ven, C., Martin, D., O'sullivan, M. J., Eardley, S., Witter, F. R., Mauldin, J., \& Newman, R. B. (2002). The association between maternal factors and perinatal outcomes in triplet pregnancies. American Journal of Obstetrics and Gynecology, 187, 752-757.

Min, S. J., Luke, B., Gillespie, B., Min, L., Newman, R. B., Mauidin, J. G., Witter, F. R., Salman, F. A., \& O’Sullivan, M. J. (2000). Birth weight references for twin. American Journal of Obstetrics and Gynecology, 182, 1250-1257.

Min, S. J., Luke, B., Misiunas, R., Nugent, C., Van de Ven, C., Martin, D., Gonzalez-Quintero, V. H., Eardley, S., Witter, F. R., Mauldin, J. G., \& Newman, R. B. (2004). Birth weight references for triplets. American Journal of Obstetrics and Gynecology, 191, 809-814.

Ministry of Education, Culture, Sports, Science and Technology (2009). Comment on the results of growth standards of Japanese children in 2008. Shoni Hoken Kenkyu (Journal of Child Health), 92, 92-124.

Ooki, S., \& Yokoyama, Y. (2003). Reference birth weight, length, chest circumference, and head circumference by gestational age in Japanese twins. Journal of Epidemiology, 13, 333-341.

Ooki, S., \& Yokoyama, Y. (2004). Physical growth carts from birth to six years of age in Japanese twins. Journal of Epidemology, 14, 151-160.

Orlebeke, J. F., Boomsma, D. I., \& Eriksson, A. W. (1993). Epidemiological and birth weight characteristics of triplets, a study from the Dutch twin register. European Journal of Obstetrics \& Gynecology and Reproductive Biology, 50, 8793.

Powls, A., Botting, N., Cooke, R. W. I., Pilling, D., \& Marlow, N. (1996). Growth impairment in very low birth-weight children at 12 years: Correlation with perinatal and outcome variables. Archives of Diseases in Childhood, 75, F152-F157.

Reilly, J. J., \& Dorosty, A. R. (1999). Epidemic of obesity in UK children. Lancet, 354, 1874-1875.

Semmler, C., Ashcroft, J., van Jaarsveld, C. H. M., Carnell, S., \& Wardle, J. (2009). Development of overweight in children in relation to parental weight and socioeconomic status. Obesity, 17, 814-820.

Silventoinen, K., Bartels, M., Posthuma, D., Burk, G. F. E., Willemsen, G., Beijsterveldt, T. C. E. M., \& Boomsma, D. I. (2007). Genetic regulation of growth in height and weight 
from 3 to 12 years of age: A longitudinal study of Dutch twin children. Twin Research and Human Genetics, 10, 354-363.

Silventoinen, K., \& Kaprio, J. (2009). Genetics of tracking of body mass index from birth to late middle age: Evidence from twin and family studies. Obesity Facts, 2, 196-202.

Silventoinen, K., Rokholm, B., Kaprio, J, \& Sørensen, T. I. A. (2010). The genetic and environmental influences on childhood obesity: A systematic review of twin and adoption studies. International Journal of Obesity, 34, 29-40.

Vogazianos, P., Fiala, J., \& Vogazianos, M. (2005). The influence of active maternal smoking during pregnancy on birth weights in Cyprus. Central European Journal of Public Health, 13, 78-84.

Wadhawan, R., Oh, W., Vohr, B. R., Wrage, L., Das, A., Bell, E. F., Laptook, A. R., Shankaran, S., Stool, B. J., Walsh, M. C., \& Higgins, R. D. (2011). Neurodevelopmental outcomes of triplets or higher-order extremely low birth weight infants. Pediatrics, 127, e654-e660.

Wilson, R. S. (1976). Concordance in physical growth for monozygotic and dizygotic twins. Annals of Human Biology, 3, 1-10.

Wilson, R. S. (1979). Twin growth: Initial deficit, recovery, and trends in concordance from birth to nine years. Annals of Human Biology, 6, 205-220.
Yokoyama, Y. (2002). Fundal height as a predictor of early preterm triplet delivery. Twin Research, 5, 71-74.

Yokoyama, Y., Shimizu, T., \& Hayakawa, K. (1995). Prevalence of cerebral palsy in twins, triplets and quadruplets. International Journal of Epidemiology, 24, 943-948.

Yokoyama, Y., Sugimoto, M., \& Ooki, S. (2005). Analysis of factors affecting birthweight, birth length and head circumference, Study of Japanese triplets. Twin Research and Human Genetics, 8, 659-663.

Yokoyama, Y., Sugimoto, M., Kaprio, J., \& Silventoinen, K. (2008). Weight growth charts from birth to six years of age in Japanese triplets. Twin Research and Human Genetics, 11, 641-647.

Yokoyama, Y., Sugimoto, M., Pitkäniemi, J., Kaprio, J., \& Silventoinen, K. (2009). Growth charts of length and height from birth to six years of age in Japanese triplets. Twin Research and Human Genetics, 12, 320-327.

Yokoyama, Y., Sugimoto, M., Pitkäniemi, J., Kaprio, J., \& Silventoinen, K. (2011). Height growth of triplets from birth to twelve years of age in Japan. Twin Research and Human Genetics, 14, 468-475.

Ziadech, S. M. (2000). The outcome of triplet versus twin pregnancies. Gynecologic and Obstetric Investigation, 50, 9699. 